\title{
Pseudomonas cepacia: a new pathogen in patients with cystic fibrosis referred to a large centre in the United Kingdom
}

\author{
E J Simmonds, S P Conway, A T M Ghoneim, H Ross, J M Littlewood
}

\begin{abstract}
Pseudomonas cepacia infection has become increasingly common among patients with cystic fibrosis in North America. In a large cystic fibrosis centre in the United Kingdom 11 cases have been identified during the last six years, with a maximum prevalence of $7 \%$ in 1988. Three patients have died, two of whom deteriorated rapidly shortly after acquisition of the organism despite intensive treatment with appropriate antibiotics. Analysis of possible causes of the increase in $P$ cepacia infection suggested that neither patient to patient transmission nor the use of nebulised antibiotics was associated with an increased risk of infection.
\end{abstract}

Most patients with cystic fibrosis die of respiratory failure secondary to chronic bacterial infection with Pseudomonas aeruginosa, Staphylococcus aureus, or Haemophilus influenzae. Recently new species of pseudomonads, in particular Pseudomonas cepacia, have been recognised as important pathogens. ${ }^{12}$ Although some patients remained stable after acquisition of the organism, many showed progressive deterioration. A subgroup of patients who had previously been mildly affected by their disease deteriorated rapidly and died shortly after acquisition of $P$ cepacia. ${ }^{2}$

Various risk factors have been suggested as predisposing to infection with $P$ cepacia including increased severity of disease, increased age, recent use of aminoglycoside antibiotics, recent admission to hospital, or a sibling already colonised with the organism. ${ }^{34}$ It is not clear if cross infection is another important contributory factor. ${ }^{56}$

$P$ cepacia has been identified more frequently in patients attending our clinic during the past six years. Two patients who had previously been mildly affected died two months and two years, respectively, after the initial isolation of the organism from their sputum. We were concerned that the regular use of nebulised antibiotics (aminoglycosides and colomycin), to which $P$ cepacia is resistant in vitro, may have been a factor in the development of infection and that patient to patient transmission may have occurred.

We report our experience of $P$ cepacia in the Leeds regional cystic fibrosis unit during the past six years.

Patients and methods

Between 1984 and 1989 the number of patients attending the cystic fibrosis clinic increased from 78 to 160 . Patients were seen at one of three clinics according to their age: an adult clinic $(n=15)$, an adolescent and young adult clinic $(n=60)$, and a paediatric clinic $(n=85)$. Inpatient admissions were to three separate wards. No attempts were made to segregate patients on the results of sputum cultures. Although inpatients slept and received treatment in separate cubicles, they were not discouraged from ordinary social interaction at other times. The notes of the 160 patients and those who had died during the study period (nine patients) were analysed retrospectively for the incidence of $P$ cepacia infection, clinical scores, use of nebulised antibiotics, and previous contact with other patients infected with $P$ cepacia.

\section{$P$ CEPACIA INFECTION}

Specimens of sputum were taken for culture at each visit to the clinic. These were mixed with an equal volume of dithiothrietol (Sputasol, Oxoid) and incubated at $37^{\circ} \mathrm{C}$ until digested. A $10 \mu \mathrm{l}$ sample of the digest was then plated onto a $P$ cepacia selective medium supplemented by $P$ cepacia Selectatab (Mast Laboratories, Liverpool). Plates were then incubated at $37^{\circ} \mathrm{C}$ and inspected daily for growth. Profiles of the antibiotic sensitivities were made of all cultures that grew organisms. Established infection was defined as isolation of the organism from six or more sputum samples obtained over at least four weeks.

SHWACHMAN CLINICAL SCORE ${ }^{7}$

This is a score that quantifies the clinical state of patients with cystic fibrosis. Points are allocated for general activity, results of physical examination, nutritional state, and radiological findings. A total of 100 points are possible; higher scores indicate better clinical condition.

PATIENTS' CONTACTS

The dates of inpatient admissions and outpatient visits were identified for each of the patients infected with $P$ cepacia. During the six month period before the isolation of the organism from the sputum of an individual patient, any visits that coincided with that of a patient known to be infected were regarded as potential contacts and noted.

NEBULISED ANTIBIOTICS

The patients with chronic pseudomonal infections were identified. The proportion of these 
who were receiving nebulised antibiotics regularly and who subsequently developed $P$ cepacia infection was compared with the proportion who remained unaffected by the organism. Colomycin, tobramycin, or gentamicin are the antibiotics normally given by nebuliser in this clinic.

\section{Results}

INCIDENCE AND PREVALENCE OF P CEPACIA INFECTION

The first case of $P$ cepacia infection was identified in 1984. A further 10 patients have since become infected (table 1$)$. Ninety $(56 \%)$ of the 160 patients were chronically infected with pseudomonads at the end of 1989. The eight surviving patients with $P$ cepacia infections accounted for $9 \%$ of this group.

\section{CLINICAL COURSE (table 2)}

At the end of 1989 the ages of patients attending the clinic ranged from $0.2-33.0$ years (mean 13.7). The age of patients at the time of their first sputum isolate of $P$ cepacia ranged from $4 \cdot 7-21 \cdot 7$ years. Five patients were male and six were female. Seven patients were from the paediatric clinic, three from the adolescent clinic, and one from the adult clinic. Infection has so far persisted from $0.3-4.7$ years.

Three of the 11 patients $(27 \%)$ have died. One patient (case 5), who was in poor condition at the time of her first infection, died three years later. $P$ cepacia infection was not thought to have influenced her prognosis. Two patients (case 6 and 8), who had mild to moderate disease, deteriorated rapidly and died two years and two months, respectively, after the onset of infection. Three surviving patients with $P$ cepacia infections have deteriorated quickly, and

Table 1 Incidence and prevalence of $P$ cepacia infection 1984-9. Figures are expressed as number (\%)

\begin{tabular}{lllr}
\hline Year & $\begin{array}{l}\text { No of } \\
\text { patients }\end{array}$ & $\begin{array}{l}\text { Incidence of } \\
\text { new cases }\end{array}$ & Prevalence \\
\hline 1984 & 78 & $1(1)$ & $1(1)$ \\
1985 & 88 & $2(2)$ & $3(3)$ \\
1986 & 105 & 0 & $3(3)$ \\
1987 & 124 & $5(4)$ & $8(6)$ \\
1988 & 139 & $3(2)$ & $10(7)$ \\
1989 & 160 & 0 & $8(5)$ \\
\hline
\end{tabular}

five remain clinically stable. In the same period six of 88 patients with chronic $P$ aeruginosa infections (7\%) have died.

\section{DEVELOPMENT OF INFECTION}

Before the isolation of $P$ cepacia, nine patients were infected with $P$ aeruginosa. Subsequently in 10 patients a mixed infection with both pseudomonads persisted. From only one patient was $P$ cepacia alone isolated.

After $P$ cepacia was first isolated from six patients, infection became rapidly established with continued growth of the organism in subsequent sputum samples. In three patients, continuous growth was preceded by an eight to 18 month period of intermittent isolations. In the remaining two patients (cases 2 and 3 ) $P$ cepacia was isolated for four and 12 months, respectively, but later cultures have grown only $P$ aeruginosa.

\section{MICROBIOLOGY}

All $P$ cepacia isolates were resistant to colomycin in vitro, and most of them were also resistant to the aminoglycosides (gentamicin, tobramycin, and amikacin) and to ciprofloxacin. Only occasional resistance was found to the ureidopenicillins (piperacillin and azlocillin) or ceftazidime.

Intravenous antibiotic treatment for infected patients was with a combination of either a ureidopenicillin or ceftazidime and an aminoglycoside. Although the $P$ cepacia was usually resistant to the latter, concurrent infection with a $P$ aeruginosa sensitive to aminoglycosides justified this practice.

\section{PATIENTS' CONTACTS}

Four of the 11 patients colonised with $P$ cepacia had no known contacts with other similarly infected patients during the six month period before their own first sputum isolation. Seven patients had few contacts (one to five potential contacts at outpatient clinics), and only one patient had prolonged inpatient contacts with known infected cases. During the two years before the isolation of $P$ cepacia, patients had not been admitted any more frequently for intravenous antibiotic treatment than patients

Table 2 Clinical course of patients infected with $P$ cepacia

\begin{tabular}{|c|c|c|c|c|c|}
\hline \multirow{2}{*}{$\begin{array}{l}\text { Case } \\
\text { No }\end{array}$} & \multirow{2}{*}{$\begin{array}{l}\text { Age at first } \\
\text { isolation } \\
\text { (years) }\end{array}$} & \multirow{2}{*}{$\begin{array}{l}\text { Length of } \\
\text { infection } \\
\text { (years) }\end{array}$} & \multicolumn{2}{|l|}{ Shwachman score } & \multirow[t]{2}{*}{ Clinical course since infection } \\
\hline & & & $\begin{array}{l}\text { Six months before } \\
\text { acquisition of } \\
\text { infection }\end{array}$ & In mid 1989 & \\
\hline $\begin{array}{l}1 \\
2 \\
3 \\
4 \\
5 \\
6 \\
7\end{array}$ & $\begin{array}{r}4.7 \\
5.7 \\
7.8 \\
9.5 \\
9.4 \\
10.5 \\
10.8\end{array}$ & $\begin{array}{l}2.5 \\
1.7 \\
1.6 \\
2.2 \\
3.0 \\
2.0 \\
4.7\end{array}$ & $\begin{array}{l}55 \\
80 \\
85 \\
85 \\
45 \\
85 \\
70\end{array}$ & $\begin{array}{r}55 \\
85 \\
70 \\
75 \\
0 \\
0 \\
75\end{array}$ & $\begin{array}{l}\text { Stable; in poor condition for age } \\
\text { Stable } \\
\text { Deterioration } \\
\text { Deterioration } \\
\text { Died } \\
\text { Died } \\
\text { Stable; requires nasogastric feeding to } \\
\quad \text { maintain weight }\end{array}$ \\
\hline $\begin{array}{r}8 \\
9 \\
10\end{array}$ & $\begin{array}{l}17 \cdot 1 \\
17 \cdot 3 \\
19 \cdot 7\end{array}$ & $\begin{array}{l}0 \cdot 2 \\
2 \cdot 4 \\
2 \cdot 4\end{array}$ & $\begin{array}{l}70 \\
65 \\
65\end{array}$ & $\begin{array}{r}0 \\
65 \\
60\end{array}$ & $\begin{array}{l}\text { Died } \\
\text { Stable } \\
\text { Deterioration; requires nasogastric feeding to } \\
\text { maintain weight }\end{array}$ \\
\hline 11 & $21 \cdot 7$ & $4 \cdot 5$ & 70 & 25 & $\begin{array}{l}\text { Deterioration; required domiciliary oxygen } \\
\text { until recent heart-lung transplant }\end{array}$ \\
\hline
\end{tabular}


infected with other pseudomonads. They had had between $0-4$ courses of treatment.

Two of the 11 patients infected with $P$ cepacia are siblings. The organism was not isolated from the sputum of the younger (case 4) until three years after the initial isolation from her elder sister (case 5). A further patient continues to be colonised only with $P$ aeruginosa 19 months after isolation of $P$ cepacia from her younger sibling (case 2), although the organism has not recently been isolated from the latter. Two patients (cases 6 and 8) had visited North America at two and four months, respectively, before they became infected with $P$ cepacia. Both had been on trips to Disneyland sponsored by charity, and had mixed freely with other children with cystic fibrosis.

\section{NEBULISED ANTIBIOTICS}

There were 99 patients (including nine dead) who had chronic pseudomonal infection. Forty of the 88 patients infected with $P$ aeruginosa $(45 \%)$ were having regular treatment with nebulised antibiotics. Of the 11 patients infected with $P$ cepacia five (45\%) had received nebulised antibiotics. This suggests that there was no association between the use of nebulised antibiotics and the development of infection.

The following case report of a fulminating infection illustrates the potential of infection with $P$ cepacia to cause an irrevocable accelerated deterioration in lung function in patients previously only mildly affected.

\section{Case report}

Case 8 was referred to the regional unit at the age of 15 years. He had been diagnosed at 3 years of age having failed to thrive, and with a persistent cough and rectal prolapse, but had remained free of serious infection and had no history of hospital admissions for respiratory problems. Initial assessment confirmed his good clinical condition with a Shwachman score of 85 , and respiratory function tests showing a forced expiratory volume in one second $\left(\mathrm{FEV}_{1}\right)$ and forced vital capacity (FVC) of $67 \%$ and $80 \%$ of predicted values, respectively.

During the next two years he remained stable, although chronically infected with $P$ aeruginosa. He received intravenous antibiotic treatment at intervals of six months. Four months before his penultimate admission he went to the United States on a trip organised by charity. He was subsequently admitted after a five week period during which he had had increased cough accompanied by green sputum, and lost his appetite. His course of treatment was uncomplicated. At discharge his $\mathrm{FEV}_{1}$ of 2.821 and FVC of 5.041 were $58 \%$ and $94 \%$, of predicted values, respectively.

Thirteen days later he was readmitted with a four day history of cough, wheeze, dyspnoea, and weight loss. Examination showed a respiratory rate of 40 /minute, crackles throughout the lung fields, and a temperature of $39^{\circ} \mathrm{C}$. He weighed $48.5 \mathrm{~kg}$ and $\mathrm{FEV}_{1}$ and $\mathrm{FVC}$ were recorded as 1.31 and 2.91, respectively. Despite intensive treatment including intravenous cefta- zidime $6 \mathrm{~g}$ daily, aztreonam $2 \mathrm{~g}$ three times a day, and lincomycin $600 \mathrm{mg}$ four times a day, parenteral feeds, and supplementary oxygen, there was no improvement.

Six days after admission $P$ cepacia was cultured from inital sputum samples. His weight had fallen to $42 \cdot 6 \mathrm{~kg}$ by 22 days, and $F E V_{1}$ and FVC to 0.771 and $1.571,15 \%$ and $28 \%$ of predicted values, respectively. At this stage a minitracheostomy (Mini-trach, Portex Ltd, Kent) was carried out, hourly suction of sputum was started, nasogastric feeds were increased gradually to supply $2 \cdot 508 \mathrm{MJ}(6000 \mathrm{kcal}) /$ day and the dose of ceftazidime was increased to $16 \mathrm{~g}$ daily. Despite initial improvement (the fever settled over the next five days, his weight increased to $46.3 \mathrm{~kg}$ over the next two weeks, and $P$ cepacia was eradicated from his sputum) the patient had a respiratory arrest. After ventilation and additional treatment with endotracheal and nebulised ceftazidime, a multiresistant Pseudomonas stutzeri was grown from sputum cultures. He died two months after $P$ cepacia had first been isolated from his sputum, and 2.5 months after his previous discharge when he had been in good clinical condition.

\section{Discussion}

This is the first report to our knowledge of $P$ cepacia infection in a large cystic fibrosis centre in the United Kingdom. The pattern of infection mirrors the experience in North America with patients showing one of three responses to the organism. ${ }^{12}$ They remained clinically stable, they deteriorated gradually over a period of months or years, or-in some previously mildly affected cases-they deteriorated rapidly. Although the prevalence of $P$ cepacia infection that we have reported is lower than that reported from North America, centres in the United Kingdom might expect a greater incidence of new cases as numbers attending clinics increase. ${ }^{8}$

As illustrated by our case report, if patients lose their lung function rapidly, intensive treatment and eventual eradication of $P$ cepacia from the sputum cannot prevent respiratory failure secondary to extensive lung damage. In similar cases histological examination of the lungs has shown widespread necrotising pneumonia with formation of microabcesses. ${ }^{9}$ These changes were more severe and extensive than those in specimens obtained from patients infected with $P$ aeruginosa. Although potential virulence factors have been identified it is not known why infection in some patients follows this fulminating course. ${ }^{10}$

The reasons for the increased prevalence of $P$ cepacia are not clear. A more widespread use of selective growth media may partly explain the increase in cases notified in North America. ${ }^{8}$ Unless a specific search is made, $P$ cepacia will not be identified as it is often overgrown by other cystic fibrosis pathogens including $S$ aureus and $P$ aeruginosa. Our own laboratories have only used selective media since 1986 , but before this were typing all colomycin resistant organisms. It is therefore unlikely that any infected cases were not identified. 
Nosocomial spread of infection has been suggested as an important factor. ${ }^{11}$ The role of patient to patient transmission remains controversial. Separation of cases infected with $P$ cepacia from non-infected patients during hospital admissions and at summer camps led to a fall in the incidence of new cases at one centre, ${ }^{6}$ but cultures from settle plates have failed to show that there is appreciable contamination of the environment of infected patients with $P$ cepacia. ${ }^{5}$ Moreover, sputum cultures of noninfected patients after contact with infected cases at summer camps, ${ }^{12}$ or as inpatients, ${ }^{5}$ showed no new $P$ cepacia infection, suggesting that the organism is not transmitted from patient to patient.

Our own experience supports the latter conclusion. In the six month period before infection developed, four of the patients $(36 \%)$ had had no known contacts with infected cases. Thus an environmental source of the organism seems unlikely. The observation of close (and in one case, prolonged) contact without infection occurring in the two sibling pairs suggests that the organism has low infectivity. None the less, we remain concerned that two of our patients had been on organised trips to America during the few months before the onset of their infection. They had previously been well but subsequently deteriorated rapidly and died. It is possible that a more virulent strain of $P$ cepacia was acquired while abroad.

It has been postulated that certain management regimens may increase patients' vulnerability to $P$ cepacia infection. Recent use of aminoglycosides has been identified as a risk factor. $^{3}$ In the laboratory the organism is uniformly resistant to colomycin, and frequently resistant to aminoglycosides (as confirmed by our observations). Long term use of these drugs in nebulised form might therefore preferentially select for $P$ cepacia colonisation. Our results do not support this hypothesis, which is an important observation because nebulised antibiotics are widely used and effective in minimising the frequency of respiratory exacerbations, ${ }^{13}$ and delaying the onset of chronic pseudomonal infection. ${ }^{14}$

$P$ cepacia is an important new pathogen in our patients with cystic fibrosis. Conflicting evidence with regard to risk factors and mode of transmission make formulation of plans for its rational management difficult. Survival is reduced among patients infected with $P$ cepacia especially among those with pre-existing severe lung disease. ${ }^{4}$ We have shown that present treatment regimens cannot reverse the rapid deterioration seen in a few patients. Until more information is available about risk factors for the acquisition and mode of transmission of $P$ cepacia, we recommend that all patients infected with $P$ cepacia should have their physiotherapy separately and sleep in individual cubicles. We are not convinced that ordinary daily social contact between infected and noninfected patients is harmful, but patient to patient transmission probably does occur in some instances of close and prolonged contact.

We thank Mr CH Ramsden for helpful microbiological advice and the Cystic Fibrosis Research Trust for funding Dr EJ Simmonds, the cystic fibrosis research fellow.

1 Isles A, Maclusky I, Corey M, et al. Pseudomonas cepacia infection in cystic fibrosis: an emerging problem. $\mathcal{F}$ Pediat 1984;104:206-10.

2 Thomassen MJ, Demko CA, Klinger JD, Stern RC. Pseudomonas cepacia colonisation in among patients with cystic fibrosis.

3 Tablan OC, Chorba TL, Schidlow DV, et al. Pseudomonas cepacia colonisation in patients with cystic fibrosis: risk faccepacia colonisation in patients with cystic fibrosis: risk fac-
tors and clinical outcome. $\mathcal{F}$ Pediatr $1985 ; 107: 382-7$.

4 Tablan OC, Martone WJ, Doershuk CF, et al. Colonisation of the respiratory tract with Pseudomonas cepacia in cystic
fibrosis. Risk factors and outcomes. Chest 1987;91:527-32.

5 Hardy KA, McGowan KL, Fisher MC, Schidlow DV. Pseudomonas cepacia in the hospital setting: lack of transmission between cystic fibrosis patients. F Pediatr 1986 109:51-4.

6 Thomassen MJ, Demko CA, Doershuk CF, Stern RC Klinger JD. Pseudomonas cepacia: decrease in colonisation in patients with cystic fibrosis. Am Rev Respir Dis 1986 134:669-71.

7 Shwachman $\dot{H}$, Kulczycki LL. Long term study of one hundred and five patients with cystic fibrosis. AMA foumal of Diseases of Children 1958;96:6-15.

8 Tablan OC, Martone WJ, Jarvis WR. The epidemiology of Pseudomonas cepacia in patients with cystic fibrosis. Eur Pseudomonas cepacia in pation

9 Tomashefski JF, Thomassen MJ, Bruce MC, Goldberg HI, Konstan MW, Stern RC. Pseudomonas cepacia-associated ponstan MW, Stern RC. Pseudomonas cepacia-associated pneumonia in cystic fibrosis. Relation of clinical features to
histopathologic patterns of pneumonia. Arch Pathol Lab histopathologic pattern

10 McKevitt AI, Woods DE. Characterisation of Pseudomonas cepacia isolates from patients with cystic fibrosis. $\mathcal{f}$ Clin Microbiol 1984;19:291-3.

11 LiPuma JJ, Mortensen JE, Dasen SE, et al. Ribotype analyses of Pseudomonas cepacia from cystic fibrosis treatmen centres. F Pediatr 1988;113:859-62.

12 Buchdahl RM, Damen Willems CE, Warner JO, Crozie DN. The Ontaria cystic fibrosis summer camp-the British experience. Proceedings of the 10th international cystic fibrosis congress, Australia 1988. Amsterdam: Excerpta Medica, 1988:99.

13 Hodson ME, Pennketh ARL, Batten JC. Aerosol carbenicillin and gentamicin treatment of Pseudomonas aeruginosa infections in patients with cystic fibrosis. Lancet 1981;ii: infections

14 Littlewood JM, Miller MG, Ghoneim AT, Ramsden CH. Nebulised colomycin for early pseudomonas colonisation in Nebulised colomycin for early pseud
cystic fibrosis. Lancet 1985;i:865. 